\title{
A atuação do Tribunal de Contas da União na concretização do direito à saúde
}

The role of the Federal Court of Accounts of Brazil in realizing the right to health

\section{Deane D'Abadia Morais ${ }^{1}$}

Resumo: O Tribunal de Contas da União (TCU) é o órgão constitucional a quem cabe exercer, em auxílio ao Congresso Nacional, a fiscalização contábil, financeira, orçamentária, operacional e patrimonial da União e das entidades da administração direita e indireta, sob os aspectos da legalidade, legitimidade e economicidade. A Constituição Federal de 1998, além de elencar o direito à saúde como um dos direitos fundamentais, ampliou as atribuições e competências do TCU, o que contribuiu para a fiscalização da efetivação deste direito por este órgão de controle. O presente artigo tem como objetivo apresentar a atuação fiscalizatória do TCU na área da saúde por meio da análise dos processos de fiscalização autuados durante os anos de 2011 a 2013. Constatou-se que os processos do tipo monitoramento foram os mais representativos $(47,6 \%)$, seguidos dos de auditoria $(31,9 \%)$. Quanto às temáticas tratadas nesses processos, a Atenção de Média e Alta Complexidade Ambulatorial e Hospitalar foi o objeto mais abordado pelas fiscalizações (32\%) e a de Investimentos na Rede de Serviços de Saúde, a segunda (12\%). Há uma diversidade na atuação do TCU, o que reforça o seu papel na concretização do direito à saúde.

Palavras-chave: Controle de políticas; Tribunal de Contas da União, Brasil; Poder Legislativo, Política de saúde.

\begin{abstract}
The Federal Court of Accounts of Brazil is a constitutional institution whose exercise, in support of the National Congress of Brazil, the accounting, financial, budgetary, operational and asset oversight of entities of the Union and the entities of the administration under the aspects of legality, legitimacy, economic and efficiency. The Federal Constitution of 1998, also listing the right to health as a fundamental right, expanded the TCU's powers and prerogatives, which contributed to the oversight of the enforcement of this right by this control entity. This article aims to show the performance of oversight TCU in health care through analysis of oversight processes litigated during the years 2011-2013. It was found that the monitoring processes were the most representative (47.6\%), followed by audit processes $(31.9 \%)$. Regarding the themes treated in these processes, the Treatment of Medium and High Complexity Outpatient Hospital was the object managed by more inspections (32\%) and Investment in Network Health Services was the second (12\%). In addition, there was a diversity action in TCU, which strengthens its role in realizing the right to health.
\end{abstract}

Keywords: Policies control; Federal Court of Accounts, Brazil; Legislative; Health policy.

\footnotetext{
${ }^{1}$ Odontóloga, Especialista em Direito Sanitário. Auditora Federal de Controle Externo do Tribunal de Contas da União (TCU). Brasília, Brasil. E-mail: deane_dm@yahoo.com.br
} 
Resumen: El Tribunal de Control de la Unión (TCU) es un órgano constitucional que actúa en auxilio del Congreso Nacional, la fiscalización contable, financiera, presupuestaria, operacional y patrimonial de la Unión y de las entidades de la administración directa e indirecta sobre los aspectos de legalidad, legitimidad y economicidad. La Constitución Federal de 1988, para allá de colocar el derecho a la salud como uno de los derechos fundamentales, amplió las atribuciones y competencias del TCU, que contribuye para la fiscalización de la efectivización de ese derecho por este órgano de control. El presente articulo tiene como objetivo presentar la actualización fiscalizadora del TCU en el área de la salud por medio del análisis de los procesos de fiscalización actuados durante los años 2011 al 2013. Se constato que los procesos del tipo de monitoramiento fueron los mas representativos $(47,6 \%)$, seguidos de los de auditoria $(31,9 \%)$. En cuanto a las temáticas tratadas en esos procesos, la Atención de Media y Alta Complejidad Ambulatorial y Hospitalar fue el objeto mas abordado por las fiscalizaciones (32\%) y de investimientos en la Red de Servicios de Salud la segunda (12\%). Además, se pudo observar una diversidad en la actuación del TCU, que refuerza su papel en la concretización del derecho a la salud.

Palabras-Ilave: Control de las políticas; Tribunal de Control de la Unión, Brasil; Poder Legislativo; Política de salud.

\section{Introdução}

A Constituição Federal de 1988 estabelece que o Congresso Nacional, mediante controle externo, desempenhará fiscalização contábil, financeira, orçamentária, operacional e patrimonial da União e das entidades da administração direta e indireta, em relação à legalidade, legitimidade, economicidade, aplicação das subvenções e renúncias de receitas. Dispõe, também, que esse controle externo deve ser exercido com o auxílio do Tribunal de Contas da União (TCU). (BRASIL, 1988)

"Constata-se que a Constituição Federal, além de estabelecer uma distinção clara entre o Congresso Nacional e o TCU, estabeleceu entre ambos uma relação de cooperação, não de subordinação ou hierárquica" (ZYMLER e ALMEIDA, 2008, p. 137). Nesse sentido, pode-se afirmar que o TCU constitui-se como órgão constitucional, autônomo e de soberania, sendo suas funções essenciais para a consolidação do Estado Democrático de Direito (ZYMLER e ALMEIDA, 2008).

A Carta Magna de 1988 ampliou as atribuições e competências do TCU (COSTA, 2006). Dessa forma, além do controle contábil, financeiro e orçamentário, realizado sob a perspectiva da legalidade, passou a ser competência deste órgão de controle a fiscalização sob aspectos operacionais e patrimoniais, inclusive em relação à legitimidade e à economicidade (CAMPELO, 2005; FERNANDES, 2012). A Constituição Federal de 
1988 demonstrou, assim, uma preocupação com a melhoria do desempenho da administração pública (CAMPELO, 2005).

A Constituição Federal de 1988 também elencou o direito à saúde como um dos direitos fundamentais, além de ampliar as competências dos Tribunais de Contas, de modo que estes órgãos possuíssem condições de fiscalizar a efetivação desses direitos, entre eles, o da saúde (COSTA, 2006; NETO, 2005; FERNANDES, 2012; RODRIGUES, 2009).

Silva (2008) assevera que a função de fiscalização é um dos meios que permitem que o princípio da legalidade seja obedecido, impondo, assim, que a administração cumpra a lei.

O TCU, no exercício de suas competências, possui nove funções básicas: fiscalizadora, judicante, sancionadora, pedagógica, consultiva, informativa, normativa, ouvidoria e corretiva (ZYMLER e ALMEIDA, 2008).

As competências atribuídas ao TCU o permitem exercer essas suas funções básicas: realizar inspeções e auditorias (função fiscalizadora); julgar as contas (função judicante); aplicar, em caso de ilegalidade de despesa ou irregularidade de contas, as sanções previstas em lei e adotar medidas para o ressarcimento dos prejuízos causados ao erário (função sancionadora); emitir orientações e recomendações (função pedagógica); emitir parecer prévio a respeito das contas prestadas pelo Presidente da República e responder a consultas formuladas por legitimados (função consultiva); enviar informações ao Congresso Nacional, expedir os alertas previstos na Lei de Responsabilidade Fiscal (LRF), e divulgar dados sobre a administração pública na internet (função informativa); editar normas (função normativa); receber denúncias (função de ouvidoria); assinar prazo para que órgão ou entidade corrija as irregularidades ou falhas detectadas, e sustar a execução do ato impugnado (função corretiva) (ZYMLER e ALMEIDA, 2008).

Em relação à função fiscalizadora, foco deste trabalho, o Regimento Interno do TCU prevê cincos instrumentos de fiscalização: levantamentos, auditorias, inspeções, acompanhamentos e monitoramentos (BRASIL, 2012f).

Por meio de levantamentos, consoante o art. 238 de seu Regimento, o TCU consolida conhecimentos sobre a organização e o funcionamento de órgãos, entidades, programas, atividades governamentais, entre outros; "[...] identifica objetos e instrumentos de fiscalização [...]"; e "[...] avalia a viabilidade da realização de fiscalizações [...]" (BRASIL, 2012f). 
A auditoria, relevante instrumento de fiscalização do TCU, é utilizada, segundo o art. 239 de seu Regimento Interno (BRASIL, 2012f), para:

I - examinar a legalidade e a legitimidade dos atos de gestão dos responsáveis sujeitos a sua jurisdição, quanto ao aspecto contábil, financeiro, orçamentário e patrimonial;

II - avaliar o desempenho dos órgãos e entidades jurisdicionados, assim como dos sistemas, programas, projetos e atividades governamentais, quanto aos aspectos de economicidade, eficiência e eficácia dos atos praticados;

III - subsidiar a apreciação dos atos sujeitos a registro.

As auditorias realizadas pelo TCU podem ser classificadas, basicamente, em dois tipos: "[...] as auditorias de conformidade, que têm como foco a legalidade dos atos administrativos, e as auditorias de natureza operacional, as quais examinam programas e ações governamentais" (BRASIL, 2014b, p. 19).

Nas auditorias de conformidade, os atos praticados por órgãos e entidades são analisados em relação a sua obediência à legislação e à jurisprudência. Por sua vez, as auditorias operacionais permitem ao TCU avaliar o resultado de programas governamentais e políticas públicas, sob os aspectos da economicidade, eficiência, eficácia e efetividade. (BRASIL, 2014b)

$\mathrm{Na}$ inspeção, outro instrumento de fiscalização, o TCU esclarece dúvidas, lacunas de informações, supressões, denúncias ou representações. Utilizando-se do acompanhamento, o Tribunal, durante um período específico, examina atos de gestão e avalia o desempenho de órgãos, entidades, sistemas, programas, e atividades governamentais. (BRASIL, 2012f)

Por fim, o "[...] monitoramento é o instrumento de fiscalização utilizado pelo Tribunal para verificar o cumprimento de suas deliberações e os resultados dela advindos" (BRASIL, 2012f).

Ao exercer sua competência constitucional, especialmente por meio de sua função fiscalizatória, o TCU tem papel de destaque na concretização do direito à saúde.

Assim, este artigo busca, a partir da análise de processos de fiscalização na área de saúde autuados no TCU no período de 2011 a 2013, apresentar um retrato da atuação deste órgão constitucional na concretização do direito à saúde, ao identificar o tipo de fiscalização realizada, bem como a temática da área da saúde abordada. 


\section{Metodologia}

Foi realizada pesquisa descritiva analítica, qualiquantitativa, dos processos do tipo fiscalização autuados no TCU e relacionados à área da saúde durante o período de 2011 a 2013. Identificou-se o instrumento de fiscalização do TCU realizado em cada um desses processos, bem como a temática abordada, de modo a realizar um retrato da atuação fiscalizatória desse órgão de controle na área da saúde nesses últimos três anos.

Para realização dessa pesquisa, foi utilizado sistema de consultas livre ao público no portal do TCU, disponível no endereço eletrônico: <http://portal2.tcu.gov.br/TCU>. Para cada ano consultado, foi utilizado como argumento de pesquisa a palavra saúde adicionada dos tipos de fiscalizações realizadas pelo TCU: saúde and levantamento, saúde and auditoria, saúde and inspeção, saúde and acompanhamento e saúde and monitoramento.

A partir dessas consultas, foi obtida a relação dos processos e suas informações básicas, totalizando 629 processos. Em seguida, cada processo foi consultado individualmente, nesse mesmo sistema de consulta, obtendo-se, assim, outras informações, como, por exemplo, histórico de tramitação e deliberações ocorridas, bem como a confirmação de que se tratava de um processo de fiscalização na área da saúde.

Nesse sentido, cabe destacar que foram excluídos após essa pesquisa processos: que não eram de fiscalização (261 processos descartados); que não tratavam sobre a saúde ou que não era possível identificar se a saúde era objeto (17 processos); de fiscalização relacionados tão somente a área meio (62 processos), como, por exemplo, fiscalizações de pessoal realizadas nos núcleos estaduais do Ministério da Saúde; os da Fundação Nacional de Saúde (Funasa) que versavam apenas sobre obras de saneamento básico, abastecimento, drenagem e melhorias habitacionais (62 processos). No entanto, foram mantidos os processos da Funasa que dispunham sobre vigilância em saúde. Ressalva-se, também, que foram mantidas as fiscalizações de pessoal realizadas em unidades de saúde.

Para permitir um retrato mais detalhado da atuação do TCU na área da saúde, identificou-se o tipo de fiscalização realizada, conforme as fiscalizações listadas no Regimento Interno do TCU (levantamentos, auditorias, inspeções, acompanhamentos e monitoramentos), e o tema tratado na fiscalização. Neste último caso, a fiscalização realizada por esse Tribunal foi classificada em uma das seguintes áreas: Atenção Básica; 
Atenção de Média e Alta Complexidade Ambulatorial e Hospitalar; Vigilância em Saúde; Assistência Farmacêutica; Gestão do Sistema Único de Saúde (SUS); Investimentos na Rede de Serviços de Saúde; e outros.

Cabe destacar que, apesar de esta classificação ter sido inspirada nos blocos de financiamento do SUS, a identificação dessas áreas em cada uma das fiscalizações do TCU não levou em consideração se os recursos fiscalizados faziam parte desses blocos de investimentos, mas, tão somente, a área objeto de fiscalização.

$\mathrm{Na}$ impossibilidade de identificar o objeto da fiscalização, como, por exemplo, no caso de processos sigilosos, o processo foi classificado em "outros". Também foram inseridos nessa classificação objetos de fiscalização que não se referiam às demais áreas, bem como os processos em que mais de uma das áreas foram fiscalizadas.

Nos processos do tipo auditoria, também classificou-se essa modalidade de fiscalização em: auditoria de conformidade, auditoria operacional e outros (impossibilidade de classificar a auditoria em alguma das duas modalidades anteriores).

Para a realização de todas essas classificações, foram utilizadas as informações públicas disponíveis para cada processo no portal do TCU, inclusive as deliberações ocorridas no âmbito de cada processo, bem como consulta ao processo originário (como, por exemplo, no caso de monitoramentos). Em alguns processos, também foram necessárias pesquisas complementares a processos apensados, realizadas no próprio portal do TCU, ao Portal da Transparência, mantido pela Controladoria-Geral da União (CGU), disponível em: < http://www.portaltransparencia.gov.br/> e ao portal do Fundo Nacional de Saúde (FNS), disponível em: <http://www.fns.saude.gov.br/indexExterno.jsf>, para identificação de objeto de convênios fiscalizados.

As consultas aos portais foram feitas no período de 1/8/2014 a 21/11/2014.

Por fim, de modo a complementar a pesquisa realizada no portal do TCU, foi feita leitura e análise dos Relatórios de Atividades do TCU, documento encaminhado ao Congresso Nacional, trimestral e anualmente, em cumprimento ao exposto no art. $71, \S 4^{\circ}$, da Constituição Federal, em que se pôde identificar os principais trabalhos de fiscalização realizados pelo TCU no período escopo deste artigo. Foram analisados os Relatórios Anuais dos anos de 2011 a 2013, os Relatórios Trimestrais dos anos de 2011 a 2013, e os Relatórios do $1^{\circ}$ e $2^{\circ}$ Trimestre de 2014. Após a leitura desses documentos, foram incluídos 11 novos processos. 


\section{Resultados e discussão}

A partir da análise dos processos, foram elencados os seguintes resultados: a) 61 processos de fiscalização no ano de 2011; b) 84 processos de fiscalização no ano de 2012 e c) 84 processos de fiscalização no ano de 2013, totalizando 229 processos.

\section{A) Tipos de fiscalização}

Durante todo o período analisado, os processos do tipo monitoramento foram os mais representativos entre os cinco tipos de fiscalização, com 109 processos $(47,6 \%)$, seguido dos de auditoria, 73 processos (31,9\%), levantamento, 40 (17,5\%), acompanhamento, 6 (2,6\%), e inspeção, 1 (0,4\%).

A expressiva participação dos processos de monitoramento deve-se ao fato que, nesse tipo de fiscalização, é verificado o cumprimento das deliberações do TCU, vindas elas também de outros tipos de processos além dos de fiscalizações, como, por exemplo, prestações de contas e tomadas de contas especiais. Além disso, uma fiscalização pode gerar mais de um monitoramento, especialmente no caso das auditorias operacionais (LIMA, 2007).

Esse significativo número de processos de monitoramento demonstra que o TCU busca não apenas expedir determinações e recomendações na área da saúde, mas, também, procura verificar o seu cumprimento, bem como os resultados advindos de suas deliberações, o que pode contribuir para a efetividade da atuação do Tribunal na área.

Ao analisar a evolução do número de processos por tipo de fiscalização no período selecionado, observou-se um significativo aumento de processos de levantamento em 2013. Esse aumento pode ser explicado pelo fato de o TCU ter realizado, no ano de 2013, diagnóstico sobre a assistência hospitalar em todos os estados da federação (BRASIL, 2014b). Conforme dados básicos dos processos analisados, o instrumento de fiscalização utilizado para esse diagnóstico foi o levantamento, o que explica o aumento desse tipo de fiscalização no ano de 2013. A Tabela 1 apresenta essa evolução. 
Tabela 1 - Quantidade de processos de fiscalização na área da saúde por tipo. Tribunal de Contas da União, 2011-2013.

\begin{tabular}{lccccc}
\hline \multirow{2}{*}{ Ano } & \multicolumn{5}{c}{ Tipos de fiscalização } \\
\cline { 2 - 6 } & Levantamento & Auditoria & Inspeção & Acompanhamento & Monitoramento \\
\hline 2011 & 9 & 19 & 0 & 1 & 32 \\
\hline 2012 & 3 & 30 & 1 & 2 & 48 \\
\hline 2013 & 28 & 24 & 0 & 3 & 29 \\
\hline Total & 40 & 73 & 1 & 6 & 109 \\
\hline
\end{tabular}

Fonte: Portal do Tribunal de Contas da União.

Em relação aos tipos de auditoria dos processos de fiscalização analisados, 71,2\% eram auditorias de conformidade e 8,2\%, auditorias operacionais, sendo que, em 15 processos, não foi possível identificar o tipo de auditoria realizada. Observou-se, durante os anos de 2011 a 2013, uma certa estabilidade do número de processos de auditorias de conformidade e um aumento, no ano de 2012, dos processos de auditorias operacionais, seguido de uma redução em 2013, não sendo encontradas explicações para esta ocorrência. A Tabela 2 apresenta esses dados.

Tabela 2 - Quantidade de processos de auditoria na área da saúde por tipo de auditoria. Tribunal de Contas da União, 2011-2013.

\begin{tabular}{lccc}
\hline \multirow{2}{*}{ Ano } & \multicolumn{3}{c}{ Tipos de auditoria } \\
\cline { 2 - 4 } & $\begin{array}{c}\text { Auditoria de } \\
\text { Conformidade }\end{array}$ & $\begin{array}{c}\text { Auditoria } \\
\text { Operacional }\end{array}$ & $\begin{array}{c}\text { Não foi possível } \\
\text { identificar }\end{array}$ \\
\hline 2011 & 14 & 1 & 4 \\
\hline 2012 & 22 & 3 & 5 \\
\hline 2013 & 16 & 2 & 6 \\
\hline Total & 52 & 6 & 15 \\
\hline
\end{tabular}

Fonte: Portal do Tribunal de Contas da União.

As auditorias operacionais realizadas pelo TCU são importantes instrumentos de fiscalização ao induzir a melhoria da eficiência e da eficácia das políticas públicas, além de promover um aumento da transparência no uso dos recursos públicos e permitir a divulgação da informação pertinente obtida sobre os resultados conhecidos por meio desse tipo de trabalho (Lima e Mafra, 2014). 
Cabe destacar que, considerando os aspectos analisados pelas auditorias operacionais - economicidade, eficiência, eficácia e efetividade (BRASIL, 2010) -, esse é um complexo tipo de fiscalização. Nesse sentido, Aguiar, Albuquerque e Medeiros (2011, p. 167), ao discorrerem sobre as auditorias operacionais, asseveram que:

Devido à variedade e complexidade das questões tratadas, possuem maior flexibilidade na escolha de temas, objetos de auditoria, métodos de trabalho e forma de comunicar as conclusões de auditoria. Empregam ampla seleção de métodos de avaliação e investigação de diferentes áreas de conhecimento, em especial das ciências sociais. [...] Algumas áreas de estudos, em função de sua especificidade, necessitam de conhecimentos especializados e abordagem diferenciada [...].

Assim, é de se esperar que, nesse tipo de trabalho, ocorra uma maior demanda de tempo e de recursos humanos, o que reflete em um número de processos de auditorias operacionais menor do que o de auditorias de conformidade. Desse modo, por se tratar de um complexo trabalho realizado pelo TCU, a abrangência e os aspectos tratados nas auditorias operacionais são mais relevantes que a quantidade realizada pelo Tribunal.

B) Áreas fiscalizadas

Quanto às áreas tratadas nas fiscalizações realizadas pelo TCU durante os anos de 2011 a 2013, a Atenção de Média e Alta Complexidade Ambulatorial e Hospitalar foi o objeto mais abordado, correspondendo a 32\% dos processos de fiscalização analisados.

A segunda área em número de processos de fiscalização foi a de Investimentos na Rede de Serviços de Saúde, com 12\% dos processos. Assistência Farmacêutica e Gestão do SUS tiveram participação semelhante no período analisado, 9\% e 8\%, respectivamente. Por fim, a Atenção Básica correspondeu a 4\% dos processos e a Vigilância em Saúde, a $2 \%$. 
Tabela 3 - Quantidade de processos de fiscalização autuados na área de saúde por área. Tribunal de Contas da União, 2011-2013.

\begin{tabular}{|c|c|c|c|c|c|c|c|}
\hline \multirow[b]{2}{*}{ Ano } & \multicolumn{7}{|c|}{ Área dos processos de fiscalização } \\
\hline & $\begin{array}{c}\text { Atenção } \\
\text { Básica }\end{array}$ & $\begin{array}{c}\text { Atenção de } \\
\text { Média e Alta } \\
\text { Complexidade } \\
\text { Ambulatorial e } \\
\text { Hospitalar }\end{array}$ & $\begin{array}{c}\text { Vigilância } \\
\text { em } \\
\text { Saúde }\end{array}$ & $\begin{array}{c}\text { Assistência } \\
\text { Farmacêutica }\end{array}$ & $\begin{array}{c}\text { Gestão } \\
\text { do } \\
\text { SUS }\end{array}$ & $\begin{array}{l}\text { Investimentos } \\
\text { na Rede de } \\
\text { Serviços de } \\
\text { Saúde }\end{array}$ & Outros \\
\hline 2011 & 2 & 12 & 2 & 6 & 7 & 8 & 24 \\
\hline 2012 & 4 & 33 & 0 & 9 & 5 & 4 & 29 \\
\hline 2013 & 3 & 29 & 3 & 6 & 6 & 16 & 21 \\
\hline Total & 9 & 74 & 5 & 21 & 18 & 28 & 74 \\
\hline
\end{tabular}

Fonte: Portal do Tribunal de Contas da União.

Um alto número de processos de fiscalização autuados na área da média e alta complexidade ambulatorial e hospitalar e na de investimentos na rede de serviços de saúde durante o período analisado demonstra que o TCU busca pautar o seu trabalho levando em consideração a materialidade, relevância e risco, aspectos presentes nessas áreas.

Na média e alta complexidade estão concentradas uma extensa e variada lista de ações, procedimentos, serviços e políticas públicas de saúde (BRASIL, 2011d). Além disso, essa área concentra expressivos gastos do SUS (BRASIL, 2011d; MACHADO, LIMA e ANDRADE, 2002).

Do mesmo modo, construções de unidades de saúde demandam uma grande quantidade de recursos financeiros, bem como são áreas relevantes e de alto risco (sujeitas a fraudes e desvio de recursos públicos).

As fiscalizações do TCU realizadas na área da Atenção Básica abrangeram a Estratégia Saúde da Família, abordando inclusive verificação do cumprimento da carga horária por profissionais das equipes e a existência de acumulação ilegal de cargos. Foram encontrados, também, processos de fiscalização cujo objeto era a gestão dos recursos da Atenção Básica. Além disso, foi realizado monitoramento das deliberações proferidas pelo TCU no âmbito de auditoria operacional nas principais estratégias da Atenção Básica.

No âmbito da Atenção de Média e Alta Complexidade Ambulatorial e Hospitalar, além de trabalhos envolvendo a prestação de serviços, os equipamentos e as aquisições 
nessa área, diversos programas e políticas foram objetos das fiscalizações do TCU nos processos analisados, como, por exemplo: Programa de Reestruturação e Contratualização dos Hospitais Filantrópicos; Programa de Doação, Captação e Transplantes de Órgãos e Tecidos; e Política Nacional de Atenção Oncológica.

Destacam-se, também, fiscalizações no sistema informatizado que dá suporte às atividades do Sistema Nacional de Transplantes (SNT); na implantação e operacionalização das Unidades de Pronto Atendimento (UPA); em contratações de serviços de hemodiálise e terapia substitutiva renal; na aquisição, controle e manutenção de mamógrafos; e na assistência hospitalar.

Como encontrado em processos na área da Atenção Básica, a acumulação irregular de cargos públicos por servidores, dessa vez em unidades hospitalares, também foi objeto de fiscalizações. Além disso, houve auditoria específica a respeito de pagamento de Adicional por Plantão Hospitalar (APH) em hospitais federais do Rio de Janeiro.

Entre os trabalhos presentes nos Relatórios de Atividades do TCU ainda nessa área estavam: levantamento em que foram constatadas irregularidades "[...] no planejamento e no processo de aquisição e de distribuição de 400 motolâncias cedidas pelo Ministério da Saúde/MS às coordenações locais do Serviço de Atendimento Móvel de Urgência (Samu)" (BRASIL, 2013d, p. 73); e auditoria que teve como objetivo avaliar os controles internos da área de licitações e contratos do Hospital Universitário Getúlio Vargas (HUGV), vinculado à Fundação Universidade do Amazonas (UFAM). (BRASIL, 2014c). Conforme Relatório Anual de Atividades do TCU (BRASIL, 2014c), esta auditoria "faz parte de um conjunto de trabalhos do TCU nos hospitais universitários de todo o país, que se originou devido ao esquema de fraude a licitações verificado no Hospital Pediátrico da Universidade Federal do Rio de Janeiro (UFRJ) [...]" (BRASIL, 2014c, p. 46).

Classificados na área de Vigilância em Saúde, além de fiscalizações na vigilância sanitária de uma maneira geral, estão objetos como a emissão de informe de avaliação toxicológica e a aplicação de recursos financeiros relativos ao bloco de vigilância em saúde. Em relação à fiscalização sobre a emissão de informe de avaliação toxicológica, segundo Relatório de Atividades do TCU referente ao $3^{\circ}$ trimestre de 2013, a auditoria realizada: 
[...] avaliou a efetividade dos procedimentos de controles adotados pela Agência Nacional de Vigilância Sanitária (Anvisa) na emissão do Informe de Avaliação Toxicológica e identificou falhas no controle interno e no fluxo de trabalho" (BRASIL, 2013a, p. 42).

Na Assistência Farmacêutica, as fiscalizações do TCU presentes nos processos analisados compreenderam os três atuais componentes do bloco de financiamento da Assistência Farmacêutica - básico, estratégico e especializado. Desse modo, foram encontradas fiscalizações na assistência farmacêutica básica; na ação atenção aos pacientes portadores de doenças hematológicas; no Programa Farmácia Popular; e na ação assistência financeira para aquisição e distribuição de medicamentos excepcionais (atual componente especializado da assistência farmacêutica).

Foram também objeto da atuação do TCU aquisições de medicamentos, destacando-se acompanhamento de licitações para compras de fatores de coagulação realizadas pelo Ministério da Saúde.

No Relatório de Atividades do TCU referente ao $2^{\circ}$ trimestre de 2011, mereceu destaque auditoria a respeito de aquisição de medicamentos no estado do Paraná, em que o Tribunal identificou:

[...] aquisição de medicamentos em quantidades incompatíveis com a demanda dos municípios, compra de medicamentos com pagamentos antecipados, licitação simulada, desvio de recursos mediante a realização de pagamentos sem que os medicamentos adquiridos tenham sido entregues e irregularidades na emissão das notas fiscais (BRASIL, 2011b, p. 39).

Classificados na área Gestão do SUS estão processos de fiscalização que tiveram como objeto: a regulação no âmbito do SUS; o controle social; controle e auditoria, incluindo levantamento a respeito do Sistema Nacional de Auditoria do SUS; o credenciamento e a contratualização de prestadores de serviços de saúde privados em complementação ao SUS; o Cartão Nacional de Saúde; e a criação de fundo municipal de saúde.

$\mathrm{Na}$ área de Investimentos na Rede de Serviços de Saúde, segunda maior área presente nos processos de fiscalização analisados, $12 \%$ do total dos processos, foram encontrados trabalhos do TCU abordando desde a construção ou a ampliação de unidades de saúde variadas, como, hospitais, unidades básicas de saúde e Unidades de Pronto 
Atendimento (UPA), até a construção da fábrica de hemoderivados e biotecnologia da Empresa Brasileira de Hemoderivados e Biotecnologia (Hemobrás).

Destaca-se que, consoante o Relatório de Atividades do TCU referente ao $1^{0}$ trimestre de 2014 (BRASIL, 2014b), o TCU realizou um conjunto de auditorias com vistas a identificação de irregularidades nas construções de UPA em todo o país.

$\mathrm{Na}$ classificação "outros", além dos casos em que não foi possível identificar o objeto do trabalho do TCU, bem como quando mais de uma área foi analisada, estão inseridas fiscalizações do TCU em diversas temáticas.

Entre as diversas temáticas abordadas está a atuação das agências reguladoras. Nesse sentido, foram objeto de fiscalizações do TCU: a atuação da Agência Nacional de Saúde Suplementar (ANS) na regulação de reajustes dos planos de saúde coletivos; a sistemática adotada pela ANS para operacionalização e fiscalização do ressarcimento efetuado pelas operadoras de saúde ao SUS em decorrência dos serviços prestados a pacientes que possuem plano de saúde; a regulação de preços de medicamentos pela Câmara de Regulação do Mercado de Medicamentos (CMED); e a arrecadação de multas aplicadas pelas ANS e Anvisa.

No campo da tecnologia da informação, encontraram-se, nos processos analisados, fiscalizações do TCU a respeito de controles gerais de tecnologia da informação e nos sistemas do Departamento de Informática do SUS (Datasus).

Outros temas tratados nos processos de fiscalizações objeto de análise deste trabalho foram inseridos também na classificação "outros" foram: a identificação e análise dos indicadores para a Política Nacional de Saúde; a emissão e renovação de Certificados de Entidades Beneficentes de Assistência Social (Cebas); o Programa Mais Médicos (acompanhamento para avaliar a legalidade e a legitimidade da criação e da implementação do programa); e as ações de prevenção de doenças, promoção e recuperação da saúde das populações indígenas.

Cabe ressalvar que diversas fiscalizações inseridas nessa classificação foram destacadas nos Relatório de Atividades do TCU, como o monitoramento em que o TCU recomendou ao Ministério da Saúde a realização de estudos a fim que se concedesse mais verbas para a Saúde. No âmbito dessa fiscalização, "[...] observou que o mínimo estabelecido legalmente tem sido interpretado como máximo a ser atingido" (BRASIL, 2013d, p. 73). Do mesmo modo, também foram apresentados nesses documentos o 
monitoramento de deliberações proferidas pelo TCU após auditoria, realizada em 2009, cujo objeto foi a avaliação do ressarcimento ao SUS dos serviços prestados a pacientes de planos de saúde; e a auditoria em que o TCU avaliou a atuação da Câmara de Regulação do Mercados de Medicamentos (BRASIL, 2013d).

Vale destacar ainda o levantamento realizado pelo TCU em que foi apresentado um diagnóstico sobre a saúde no Brasil, denominado Relatório Sistêmico de Fiscalização da Saúde, em que foi feito uma consolidação dos trabalhos do TCU mais relevantes na área da saúde. Nesse levantamento, por meio de indicadores, o TCU "[...] constatou significativas desigualdades, tanto na comparação do modelo público com o privado, quanto dentro do próprio Sistema Único de Saúde (SUS), quando comparadas as regiões do País e as capitais e o interior" (BRASIL, 2014b, p. 40). Nesse mesmo trabalho, foi apresentado, também, resultado de um diagnóstico da assistência hospitalar realizado em 116 hospitais públicos (BRASIL, 2014b).

As ações do TCU estão, gradativamente, focando a análise do desempenho da administração pública, não esquecendo, porém, o exame da legalidade (ZYMLER e ALMEIDA, 2008). Nesse sentido, "[...] é importante que a Sociedade Civil veja o Tribunal como um agente capaz de avaliar as políticas públicas e propor soluções adequadas para os problemas e para as carências que afligem os brasileiros" (ZYMLER e ALMEIDA, 2008, p. 153).

No atual contexto brasileiro, em que valores democráticos são valorizados e os direitos fundamentais necessitam de uma efetivação mais ampla, as atribuições das Corte de Contas adquirem uma maior importância (FERNANDES, 2012).

O controle exercido atualmente pelos Tribunais de Contas é um controle de resultados, focado em aspectos qualitativos do gasto público, não se atendo apenas a aspectos de legalidade. Nesse sentido, a Constituição de 1988, além de prever expressamente um controle sob aspectos de legitimidade e economicidade, demonstrou a necessidade de um controle direcionado à concretização efetiva dos direitos fundamentais, exercido sob aspectos qualitativos e de otimização dos gastos públicos (FERNANDES, 2012). 


\section{Considerações finais}

A Constituição Federal de 1988 estabeleceu que a saúde é direito de todos e dever do estado. No entanto, para que esse direito seja efetivamente posto em prática, não basta apenas a ação do poder executivo na elaboração e execução de políticas públicas, bem como do poder legislativo na criação de normas. Assim, é de extrema importância que exista um órgão independente que avalie e controle a concretização desse direito fundamental.

Nesse sentido, a Carta Magna dispôs que o controle externo deve ser exercido pelo Congresso Nacional com o auxílio do Tribunal de Contas da União (TCU). Conforme apresentado, a Constituição Federal de 1988 concomitantemente elencou o direito à saúde como um dos direitos fundamentais e aumentou as atribuições e competências do TCU, que passou a realizar fiscalizações também sob aspectos operacionais e patrimoniais, inclusive em relação à legitimidade e à economicidade.

Diante do exposto, esse trabalho, por meio da análise de processos de fiscalização na área de saúde autuados no TCU durante os anos de 2011 a 2013, apresentou a atuação fiscalizatória desse órgão de controle na área da saúde nesses três anos.

Constatou-se que os principais instrumentos de fiscalização presentes nos processos autuados nesse período pelo TCU foram o monitoramento e a auditoria, sendo as principais áreas fiscalizadas a Atenção de Média e Alta Complexidade Ambulatorial e Hospitalar e Investimentos na Rede de Serviços de Saúde.

O grande número de monitoramentos realizados demonstra que o TCU busca verificar o cumprimento e o resultado de suas deliberações, o que pode colaborar para a efetividade de seu papel na concretização do direito à saúde. A presença da auditoria como segundo instrumento de fiscalização mais realizado nos processos analisados confirma o papel do TCU como órgão de avaliação e controle do direito à saúde.

Já a sua expressiva atuação nessas áreas - média e alta complexidade ambulatorial e hospitalar e investimentos na rede de serviços de saúde - ratifica que o TCU tem levado em consideração a materialidade, relevância e risco ao direcionar suas ações fiscalizatórias, uma vez que esses são aspectos presentes nessas áreas.

Cabe ressaltar, também, que, por meio das análises realizadas neste trabalho, foi possível observar a diversidade da atuação fiscalizatória do TCU na área da saúde, 
reforçando o importante papel deste órgão constitucional na concretização do direito à saúde.

Por fim, destaca-se a importância da realização de estudos futuros que detalhem a atuação do TCU na concretização do direito à saúde, permitindo, desse modo, identificar os resultados de sua atuação.

\section{Referências bibliográficas}

AGUIAR, U. D. de; ALBUQUERQUE, M. A. S. de e MEDEIROS, P. H. R. A administração Pública sob a perspectiva do controle externo. Belo Horizonte: Fórum, 2011. 520 p.

BRASIL. Tribunal de Contas da União. Relatório Trimestral de Atividades: $2^{\circ}$ trimestre de 2014. Brasília: TCU, Secretaria-Geral da Presidência, 2014a. 111 p. Disponível em: http://portal2.tcu.gov.br/portal/page/portal/TCU/publicacoes institucionais/relatorios/relatori os atividades/Relat\%C3\%B3rio\%20de\%20Atividades\%20TCU 2\%C2\%BA\%20Trim2014Com\%20CAPA.pdf Acesso em: 20 nov. 2014.

BRASIL. Tribunal de Contas da União. Relatório Trimestral de Atividades: $1^{\circ}$ trimestre de 2014. Brasília: TCU, Secretaria-Geral da Presidência, 2014b. 98 p. Disponível em: http://portal2.tcu.gov.br/portal/page/portal/TCU/publicacoes institucionais/relatorios/relatori os atividades/2014 Relat\%C3\%B3rio\%20de\%20Atividades 1\%C2\%BA Trimestre 30Mai o2014 v.pdf Acesso em: 20 nov. 2014.

BRASIL. Tribunal de Contas da União. Relatório Anual de Atividades: 2013. Brasília: TCU, Secretaria-Geral da Presidência, 2014c. 119 p. Disponível em: http://portal2.tcu.gov.br/portal/page/portal/TCU/publicacoes institucionais/relatorios/relatori os atividades/2013 Relat\%C3\%B3rio\%20Anual\%20de\%20Atividades.pdf Acesso em: 20 nov. 2014.

BRASIL. Tribunal de Contas da União. Relatório Trimestral de Atividades: 4ํㅡㄹ trimestre de 2013. Brasília: TCU, Secretaria-Geral da Presidência, 2014d. 118 p. Disponível em:

http://portal2.tcu.gov.br/portal/page/portal/TCU/publicacoes institucionais/relatorios/relatori os atividades/2013 Relat\%C3\%B3rio 4\%C2\%BA Trimestre Final Vers\%C3\%A302.pdf .Acesso em: 20 nov. 2014.

BRASIL. Tribunal de Contas da União. Relatório Trimestral de Atividades: $3^{\circ}$ Trimestre. Brasília: TCU, Secretaria-Geral da Presidência, 2013a. 128 p. Disponível em:

http://portal2.tcu.gov.br/portal/page/portal/TCU/publicacoes institucionais/relatorios/relatori os atividades/2013 Relat\%C3\%B3rio-de-Atividades 3\%C2\%BA Trimestre.pdf Acesso em: 21 nov. 2014.

BRASIL. Tribunal de Contas da União. Relatório Trimestral de Atividades: 20 Trimestre de 2013. Brasília: TCU, Secretaria de Planejamento, Governança e Gestão, 2013b. 132 p. Disponível em:

http://portal2.tcu.gov.br/portal/page/portal/TCU/publicacoes institucionais/relatorios/relatori os atividades/2013 Relat\%C3\%B3rio de Atividades 2\%C2\%BA Trimestre.pdf Acesso em: 21 nov. 2014. 
BRASIL. Tribunal de Contas da União. Relatório Trimestral de Atividades: 2013. Brasília: TCU, Secretaria de Planejamento, Governança e Gestão, 2013c. 110 p. Disponível em: http://portal2.tcu.gov.br/portal/page/portal/TCU/publicacoes institucionais/relatorios/relatori os atividades/2013 Relat\%C3\%B3rio 1\%C2\%BA Trimestre 02Jun2013.pdf Acesso em: 21 nov. 2014.

BRASIL. Tribunal de Contas da União. Relatório Anual de Atividades: 2012. Brasília: TCU, Secretaria de Planejamento, Governança e Gestão, 2013d. 159 p. Disponível em: http://portal2.tcu.gov.br/portal/page/portal/TCU/publicacoes institucionais/relatorios/relatori os atividades/2012 Relat\%C3\%B3rio anual de Atividades.pdf Acesso em:: 21 nov. 2014]

BRASIL. Tribunal de Contas da União. Relatório Trimestral de Atividades: 4ำ Trimestre de 2012. Brasília: TCU, Secretaria de Planejamento, Governança e Gestão, 2013e. 118 p. Disponível em:

http://portal2.tcu.gov.br/portal/page/portal/TCU/publicacoes institucionais/relatorios/relatori os atividades/2012 Relat\%C3\%B3rio 4\%C2\%BA Trimestre.pdf Acesso em: 21 nov. 2014.

BRASIL. Tribunal de Contas da União. Relatório Trimestral de Atividades: $3^{\circ}$ Trimestre de 2012. Brasília: TCU, Secretaria de Planejamento e Gestão, 2012a. 110 p. Disponível em: http://portal2.tcu.gov.br/portal/page/portal/TCU/publicacoes institucionais/relatorios/relatori os atividades/2012 Relat\%C3\%B3rio 3\%C2\%BA Trimestre.pdf Acesso em: 21 nov. 2014.

BRASIL. Tribunal de Contas da União. Relatório Trimestral de Atividades: $2^{\circ}$ Trimestre de 2012. Brasília: TCU, Secretaria de Planejamento e Gestão, 2012b. 120 p. Disponível em: http://portal2.tcu.gov.br/portal/page/portal/TCU/publicacoes institucionais/relatorios/relatori os atividades/2012 Relat\%C3\%B3rio 2\%C2\%BA Trimestre.pdf Acesso em: 21 nov. 2014

BRASIL. Tribunal de Contas da União. Relatório Trimestral de Atividades: 1ำ Trimestre de 2012. Brasília: TCU, Secretaria de Planejamento e Gestão, 2012c. 104 p. Disponível em: http://portal2.tcu.gov.br/portal/page/portal/TCU/publicacoes institucionais/relatorios/relatori os atividades/2012 Relat\%C3\%B3rio 1\%C2\%BA Trimestre COM\%20ALTERA\%C3\%87 \%C3\%95ES.pdf Acesso em: 21 nov. 2014.

BRASIL. Tribunal de Contas da União. Relatório Anual de Atividades: 2011. Brasília: TCU, Secretaria de Planejamento e Gestão, 2012d. 123 p. Disponível em:

http://portal2.tcu.gov.br/portal/page/portal/TCU/publicacoes institucionais/relatorios/relatori os atividades/2011 Relat\%C3\%B3rio Anual Atividades.pdf Acesso em: 21 nov. 2014.

BRASIL. Tribunal de Contas da União. Relatório de Atividades: 4ํㅜ Trimestre de 2011. Brasília: TCU, Secretaria de Planejamento e Gestão, 2012e. 87 p. Disponível em: http://portal2.tcu.gov.br/portal/page/portal/TCU/publicacoes institucionais/relatorios/relatori os atividades/2011 Relat\%C3\%B3rio 4\%C2\%BA trimestre.pdf Acesso em: 21 nov. 2014. 
BRASIL. Tribunal de Contas da União. Resolução TCU № 246, de 30 de novembro de 2011, que altera o Regimento Interno do Tribunal de Contas da União, aprovado pela Resolução TCU no 155, de 4 de dezembro de 2002. Disponível em:

http://portal2.tcu.gov.br/portal/page/portal/TCU/normativos/sobre normativos/regimento.pdf Acesso em: 20 nov. 2014.

BRASIL. Tribunal de Contas da União. Relatório de Atividades: 3ํo Trimestre de 2011. Brasília: TCU, Secretaria de Planejamento e Gestão, 2011a. 94 p. Disponível em: http://portal2.tcu.gov.br/portal/page/portal/TCU/publicacoes institucionais/relatorios/relatori os atividades/2011 Relat\%C3\%B3rio 3\%C2\%BA trimestre Revis\%C3\%A3o.pdf Acesso em: 21 nov. 2014.

BRASIL. Tribunal de Contas da União. Relatório de Atividades: 2o Trimestre de 2011. Brasília: TCU, Secretaria de Planejamento e Gestão, 2011b. 92 p. Disponível em: http://portal2.tcu.gov.br/portal/page/portal/TCU/publicacoes institucionais/relatorios/relatori os atividades/Novo 2011 Relat\%C3\%B3rio 2\%C2\%BA trimestre.pdf Acesso em: 21 nov. 2014.

BRASIL. Tribunal de Contas da União. Relatório de Atividades: 1ำ Trimestre de 2011. Brasília: TCU, Secretaria de Planejamento e Gestão, 2011c. 82 p. Disponível em: http://portal2.tcu.gov.br/portal/page/portal/TCU/publicacoes institucionais/relatorios/relatori os atividades/2011 Relat\%C3\%B3rio 1\%C2\%BA trimestre.pdf. Acesso em: 21 nov. 2014.

BRASIL. Conselho Nacional de Secretários de Saúde. Assistência de Média e Alta Complexidade no SUS. Brasília: CONASS, 2011d. 223 p.

BRASIL. Tribunal de Contas da União. Manual de Auditoria Operacional. Brasília: TCU, Secretaria de Fiscalização e Avaliação de Programas de Governo (Seprog), 2010. Disponível em:

http://portal2.tcu.gov.br/portal/pls/portal/docs/2058980.PDF . Acesso em: 21 nov. 2014]

BRASIL. Constituição da República Federativa do Brasil de 1988. Disponível em:

http://www.planalto.gov.br/ccivil 03/constituicao/ConstituicaoCompilado.htm Acesso em: 20 nov. 2014]

CAMPELO, V. O Tribunal de Contas no Ordenamento Jurídico Brasileiro. Em: O Novo Tribunal de Contas: órgão protetor dos direitos fundamentais. Belo Horizonte: Fórum, 2005. $248 \mathrm{p}$.

COSTA, L. B. D. Tribunal de Contas: evolução e principais atribuições no Estado Democrático de Direito. Belo Horizonte: Fórum, 2006. 165 p.

FERNANDES, E. B. D. A efetividade do controle externo das contas públicas - Elementos teóricos e práticos de otimização do controle exercido pelos Tribunais de Contas. Revista Brasileira de Direito Público. Belo Horizonte, v.37, n.10, p. 143-170, abr./jun. 2012.

LIMA, L. H. Controle externo: teoria, legislação, jurisprudência e questões de concursos.

Rio de Janeiro: Elsevier, 2007. 496 p. 
LIMA, M. L. e MAFRA, F. Auditoría de Desempeno en el TCU. Revista de la Organización Latinoamericana y del Caribe de Entidades Fiscalizadoras Superiores, v.15, n.7, p. 23-28, 2014.

http://bibliotecavirtual.olacefs.com/gsdl/collect/revistas/archives/HASH281d.dir/Revista15.p df Acesso em: 20 nov. 2014.

MACHADO, C. V.; LIMA, L. D. e ANDRADE, C L. T. O financiamento federal da política de saúde no Brasil: tendências e desafio. Revista de Políticas Públicas e Gestão Governamental, Brasília, v. 13, n.1, p.7-22, jan-jun. 2014.

NETO,D. F. M. O Parlamento e a Sociedade como Destinatários do Trabalho dos Tribunais de Contas. Em: O Novo Tribunal de Contas: órgão protetor dos direitos fundamentais. Belo Horizonte: Fórum, 2005. 248 p.

RODRIGUES, A. P. A atuação do Tribunal de Contas da União na gestão compartilhada da Saúde - análise a partir do controle social. 2009. Tese de mestrado em Direito. Universidade Luterana do Brasil, Canoas, 2009.

SILVA, J. A. Curso de Direito Constitucional Positivo. São Paulo: Malheiros Editores, 2008. $926 \mathrm{p}$.

ZYMLER, B. e ALMEIDA, G. H. R. O Controle Externo das Concessões de Serviços Públicos e das Parcerias Público-Privadas. Belo Horizonte: Fórum, 2008. 412 p. 